\title{
Outcome of Near Miss Cases in a Periurban Hospital
}

\author{
S NAZMEEN $^{\mathrm{a}}, \mathrm{S}$ TASNIM $^{\mathrm{b}}$, I ARA ${ }^{\mathrm{c}}$
}

\begin{abstract}
Summary:
A near miss or severe acute maternal morbidity (SAMM) means a woman (in pregnancy /abour/puerperium) who was almost dead but survived. It is often poor, socially excluded women that suffer most.
\end{abstract}

The objective of this study was to explore the outcome of near miss cases admitted in the hospital along with their presentation, socio demographic characteristic and medical and surgical intervention needed.

It was a cross sectional study conducted from $1^{\text {st }}$ July 2009 to $31^{\text {st }}$ December 2009 at Institute of Child and Mother Health. Among cases who got admitted in the hospital in moribund condition with pregnancy related complications. Total 91 patients were enrolled consecutively. Data were collected by structured questionnaires. Analysis was done using SPSS program.

About $72 \%$ of women were at second decade of their lives and $71 \%$ of them were from poor socioeconomic condition. About 39\% patients did not take any antenatal checkup.

\section{Introduction:}

A near miss or severe acute maternal morbidity means a woman (in pregnancy/ labour/ peurperium) who was almost dead but survived by chance ${ }^{1}$. A "near miss" used to be thought of as a case where a woman had a near brush with death; she would have died were good fortune and medical care not on her side. This characterization was also used for women with severe organ dysfunction or organ failure who survived, that is with intensive medical intervention, a maternal death was avoided and turned into a survival ${ }^{2}$.

SAMM refers to the morbidity a woman actually suffers. Essentially, it can be thought of a pyramid of disease in pregnancy, the base being the numerically larger general

a. Dr. Summyia Nazmeen, Junior consultant, Department of Obstetrics \& Gynaecology, Centre for Women and Child Health.

b. Prof. Saria Tasnim, Professor \& Head, Department of Obstetrics \& Gynaecology, Centre for Women and Child Health.

c. Prof. Iffat Ara, Professor, Department of Obstetrics \& Gynaecology, Popular Medical College.

Address of the Correspondence: Summyia Nazmeen, Centre for Woman and Child Health, Postal address : Flat D-5. Sal Amanellae Apartments. House 12. Road 126. Gulshan 1. Dhaka 1212. Mobile: 01817017112.E mail: mhz4261@gmail.com

Received: 15 June 2017

Accepted: 20 Dec. 2017
Eclampsia (43\%) was the prime cause of SAMM. Next were postpartum haemorrhage (17\%), obstructed labour (11\%), antepartum haemorrhage (6\%), ectopic pregnancy (6\%), chorioamnionitis (4\%), severe preeclampsia (4\%), septic abortion (2\%), ruptured uterus (2\%), uterine perforation (1\%), shock (2\%), puerperal sepsis (1\%), and severe anaemia (1\%). Along with medical care, surgical intervention such as LUCS, D\&C, salphingoophorectomy, hysterectomy were needed for the management of SAMM. More than 4 bags of blood transfusion needed in $24.50 \%$ of patients. Only 4\% patients needed ICU admission.

Most of the causes of SAMM were apparently preventable. Awareness and education about the danger signs of pregnancy, proper antenatal care, delivery by skilled birth attendant and proper auditing of care provided will be helpful to prevent SAMM.

Key Words: Near miss, Outcome of pregnancy, Severe acute maternal morbidity (SAMM).

(J Bangladesh Coll Phys Surg 2018; 36: 20-25)

pregnant population, the "tip of ice berg" being maternal death and much hidden morbidity beneath the surface ${ }^{2}$.

Definition of near miss or acute maternal morbidity cases varied among different studies. Three types of approaches have been proposed for defining life threatening obstetric complications and near miss events, those are based on management, clinical sign and symptom and organ systems respectively ${ }^{2}$. By Mental GD et el, a near miss describes a patient with acute organ system dysfunction, which if not treated appropriately, could result in death ${ }^{3}$. Prual A et el, has defined severe maternal morbidity as severe complications from $28^{\text {th }}$ weeks of gestation to $42^{\text {nd }}$ day postpartum that would have resulted in death of the mother or a definite invalidating sequels without medical intervention ${ }^{4}$. Some studies have used intensive care unit admission to define near miss morbidity ${ }^{3}$.

In some studies management criteria was used in the definition of life threatening complications and that include the cases requiring use of emergency hysterectomy, caesarean section, hospitalization for more than four days and anesthetic accident ${ }^{3,5}$. 
Severe maternal morbidity is prevalent throughout the world, mostly in the developing countries. It is often poor, socially excluded women that suffer most. Incidence of SAMM vary between $0.80 \%-8.23 \%$ in studies that use disease specific criteria while the range is $0.38 \%-1.09 \%$ in the group that use organ system based criteria and included unselected group of women. The rates are within the range of $.01 \%$ and $2.99 \%$ in studies using management based criteria ${ }^{6}$. There is a big difference of incidence of severe acute maternal morbidity cases between developing (South Africa 1:5; India and Niger 1:11) and developed countries (UK $1: 118$, France $1: 222)^{7}$.

The concept of "the three delays" was developed to analyze the obstacles that threaten to postpone treatment of women with obstetric complications ${ }^{8}$. Any delay in either of three phases of delay would likely to aggravate SAMM. The first phase of delay involves the decision to seek care. Recognition of illness is defined by the patient's view, not by the criteria defined by the health workers?.

The second phase of delay concerns transport, the time from the decision to facility where this assistance is expected. Distribution of facilities, distance and nonexistent public transports are the main problem in a situation where there is "too far to walk" .

The third delay is perhaps most crucial as it reflects the receiving of appropriate treatment in time. Insufficient and unqualified staffs, mismanagement of patients, unavailability of blood and storage of essential drugs and equipment constitute the third delay at many places 9 . The level of delay interconnect in the way that low quality of care at the third level and long distance and troublesome transports at the second level will affect the decision making at first level ${ }^{9}$.

Objective of the study was to see the outcome of near miss cases admitted in the hospital along with their presentation, socio demographic characteristics and treatment required for near miss cases.

\section{Methodology:}

It was a cross sectional study conducted at Institute of Child and Mother Health from $1^{\text {st }}$ July 2009 to $31^{\text {st }}$ December 2009.

Among the cases who got admitted in the Gynae \& Obstetrics department of hospital in moribund condition with severe preeclampsia and eclampsia (diagnosed with the history of convulsion, hypertension, urine albumin), postpartum haemorrhage (diagnosed with the finding of vaginal bleeding, maternal hypothermia, tachycardia, loss of consciousness, hypotension, number of pad soaked), obstructed labour (diagnosed with prolong labour, dehydration, fetal distress), ectopic pregnancy (diagnosed with history of amenorrhoea and pain in abdomen, tachycardia, syncopal attack or loss of conciousness), puerperal sepsis (diagnosed with subinvolution of the uterus, fever, uterine tenderness, foul smelling vaginal discharge), severe anaemia (diagnosed with the finding of palor, tachycardia, low $\mathrm{Hb}$ level), shock (diagnosed with the finding of hypotension, hypothermia, tachycardia with or without unconciousness), septic abortion (diagnosed with the history of abortion, fever, foul smelling vaginal discharge), ruptured or perforated uterus (diagnosed with the finding of tachycardia, per vaginal bleeding, shock). Total 91 patients were enrolled consecutively during study period.

Patient who died following severe morbidity were excluded from the study.

Data was collected from hospital records and interviewing patients and their attendants using structured questionnaire. Ethical clearance was obtained from ethical review committee of Institute of Child and Mother Health. Written informed consent was obtained from the patients. Data analysis was done by using SPSS program.

\section{Result:}

Most of the SAMM cases were in 21-30 years of age group $(72 \%)$ and $71 \%$ was of low socio economic condition. About $60 \%$ were multi para (Table 1). More than one third patients had no antenatal checkup. One third $(1 / 3)$ patient took antenatal care less than four times (Table 2). Most frequent presentation was convulsion (43\%), bleeding 30.77\%, about 5.5\% were unconcious. Hyperthermia present in $14.3 \%, 17.6 \%$ had severe anaemia and $17 \%$ had dehydration (Table 3). The incidence of eclampsia was the highest (43\%) followed by postpartum haemorrhage (17\%), obstructed labour (11\%), antepartum haemorrhage (6\%), ectopic pregnancy $(6 \%)$, severe preeclampsia $(4 \%)$, chorioamnionitis $(4 \%)$, ruptured uterus, septic abortion and shock (2\%), uterine perforation and 
puerperal sepsis (1\%) (Figure1). Regarding treatment, anticonvulsant (37.3\%), antibiotics (49.4\%), uterotonic drugs (32.96\%), antihypertensive drug (14.2\%) were commonly prescribed. Blood transfusion was needed in more than half of the patients and $24.5 \%$ need more than 4 bags of blood (Figure 2). Common surgical interventions were LUCS (60.3\%), NVD (13.2\%), D\&C (10.3\%) and 3\% needed salphingoophorectomy, repair of cervical tear and hysterectomy respectively (Figure 3). $4.4 \%$ needed ICU admission (Table 4). Maximum patients (59.3\%) stayed in the hospital for 5-8 days. $10.9 \%$ patients stayed for more than 12 days (Table 5). During discharge $86.7 \%$ patients were well and $13.3 \%$ patients had some sorts of morbidity. Types of morbidities were hysterectomy (16.67\%), salphingoophorectomy $(16.67 \%)$, renal failure $(8.34 \%)$, heart failure $(8.34 \%)$, chronic hypertension (41.65\%) and Sheehan's Syndrome (8.34\%) (Table 6). Among all these patients, 2 patients died during the study period.

\section{Table-I}

\begin{tabular}{|c|c|c|}
\hline \multicolumn{3}{|c|}{ Socio Demographic Characteristics } \\
\hline $\begin{array}{l}\text { Socio Demographic } \\
\text { Characteristics }(n=91)\end{array}$ & Number & $\%$ \\
\hline
\end{tabular}

\begin{tabular}{lll}
\hline Age & & \\
$<20$ & 11 & $12 \%$ \\
$21-30$ & 66 & $72 \%$ \\
$31+$ & 14 & $15 \%$
\end{tabular}

Occupation

House Wife

Day Labour

$\begin{array}{cc}90 & 99 \% \\ 1 & 1 \%\end{array}$

Socio Economic Condition

\begin{tabular}{lll} 
Poor & 65 & $71 \%$ \\
Middle Class & 16 & $18 \%$ \\
Lower Middle Class & 10 & $11 \%$ \\
Parity & & \\
Primi & 36 & $40 \%$ \\
Multi & 55 & $60 \%$ \\
\hline
\end{tabular}

Table-II

No. of Antenatal Visit in Current pregnancy

\begin{tabular}{lcc} 
No. of Antenatal Visit & Number & $\%$ \\
\hline No Visit & 36 & $39.60 \%$ \\
$1-4$ & 40 & $44.00 \%$ \\
More Than 4 & 15 & $16.40 \%$ \\
\hline
\end{tabular}

Table-III
Distribution According to Clinical Feature of the Study Population

\begin{tabular}{ll} 
Complications & Number $\quad \%$ \\
\hline
\end{tabular}

Convulsion $(\mathrm{n}=39)$

Antepartum

$31 \quad 79.48 \%$

Postpartum

$8 \quad 21.52 \%$

Bleeding $(\mathrm{n}=28)$

$\begin{array}{lll}\text { Antepartum } & 7 & 25.00 \%\end{array}$

Postpartum $\quad 21 \quad 75.00 \%$

Oedema $(\mathrm{n}=91)$

Present $\quad 31 \quad 34.06 \%$

Absent $60 \quad 65.94 \%$

Conciousness $(\mathrm{n}=91)$

Concious $\quad 73 \quad 80.20 \%$

Semi Concious $\quad 13 \quad 14.30 \%$

Unconcious $\quad 5 \quad 5.50 \%$

Temperature $(\mathrm{n}=91)$

Hypothermia $(<97.5 \mathrm{~F}) \quad 2 \quad 2.20 \%$

Normothermia (97.5-99.5 F) $\quad 76 \quad 83.50 \%$

Hyperthermia $(>99.5 \mathrm{~F}) \quad 13 \quad 14.30 \%$

Blood Pressure $(\mathrm{n}=91)$

Systolic (More than 140) $\quad 28 \quad 30.70 \%$

Diastolic (More Than 90) $\quad 36 \quad 39.50 \%$

Anaemia $(\mathrm{n}=91)$

No Anaemia $\quad 12 \quad 13.10 \%$

Mild $\quad 45 \quad 49.50 \%$

Moderate $\quad 18 \quad 19.80 \%$

Severe $\quad 16 \quad 17.60 \%$

Dehydration $(\mathrm{n}=91)$

Nil $\quad 76 \quad 83 \%$

Moderate $\quad 12 \quad 13 \%$

Severe $\quad 3 \quad 4 \%$




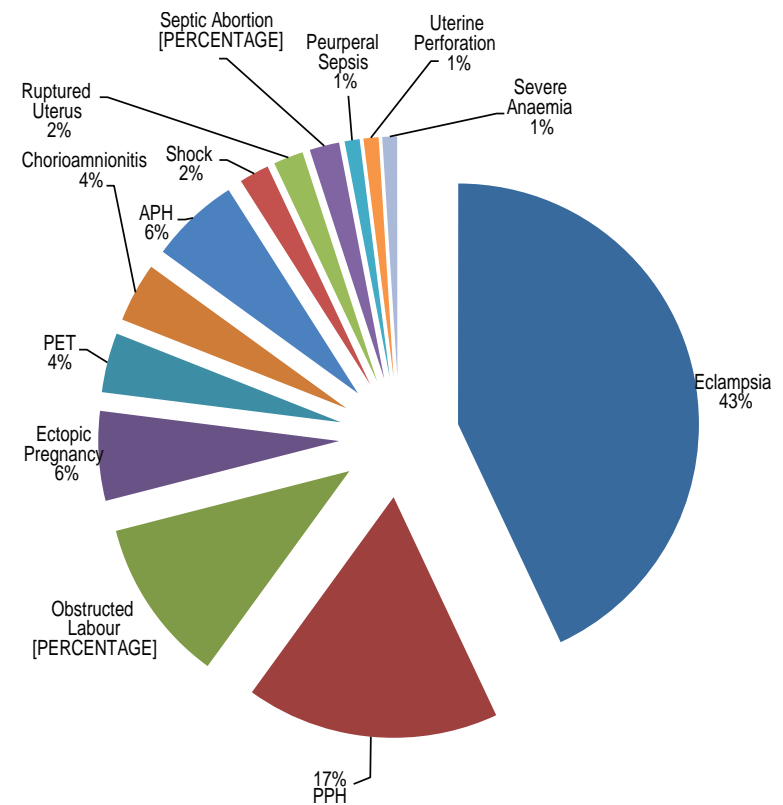

Fig.-1: Diagnosis at the time of Admission

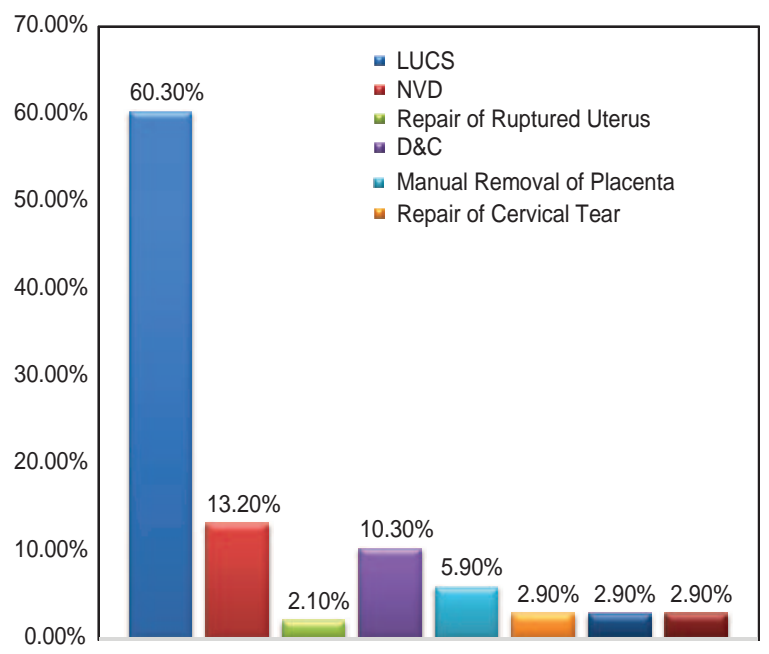

Fig.-3: Distribution of Patients by Surgical Treatment Required

\section{Table-IV}

Distribution According to Admission Required in ICU

\begin{tabular}{lcc}
$\begin{array}{l}\text { Admission Required } \\
\text { in ICU }(\mathrm{n}=91)\end{array}$ & Number & $\%$ \\
\hline Yes & 4 & $4.4 \%$ \\
No & 87 & $95.6 \%$ \\
\hline
\end{tabular}

Table-V

Distribution of Patients by Duration of Hospital Stay

\begin{tabular}{lcc} 
Number of Days & Number & $\%$ \\
\hline $1-4$ & 14 & $15.3 \%$ \\
$5-8-$ & 54 & $59.3 \%$ \\
$9-12$ & 13 & $14.2 \%$ \\
More than 12 & 10 & $10.9 \%$ \\
\hline
\end{tabular}

\section{Table-VI}

Distribution of Patients According to Type of Morbidity

Types of Morbidity $(\mathrm{n}=12) \quad$ Number $\quad \%$

$\begin{array}{lll}\text { Hysterectomy } & 2 & 16.67 \%\end{array}$

Salphingoophorectomy $2 \quad 16.67 \%$

Renal Failure $\quad 1 \quad 8.34 \%$

Heart Failure $\quad 1 \quad 8.34 \%$

Chronic Hypertension $\quad 5 \quad 41.65 \%$

Sheehan's Syndrome $\quad 1 \quad 8.34 \%$

Fig.-2: Distribution of Patients by Medical Treatment Required 


\section{Discussion:}

This study represents a fraction of scenario of severe acute maternal morbidity in Bangladesh. The study shows that $72 \%$ of the affected women are in the second decade of their lives and majority of them are from poor socio economic condition. Zwart and Richters et el, show in Netherland incidence of SAMM is more in age $20-35$ years, it is about $70 \%$ and they are from middle socioeconomic status $(44 \%)^{10}$.

According to this study about $39 \%$ patients had not taken any antenatal checkup. Those who took antenatal check up most of them went to government hospital. In Netherland, $85 \%$ of women start prenatal care by community midwives. In case of complication during pregnancy or labour, care is taken over by an obstetrition $^{11}$. In India, similar of their cases shows that $61.9 \%$ are not registered for antenatal care ${ }^{12}$.

Identifying women at risk is important. The risk factors of severe maternal morbidities have been identified as maternal age more than 34, social exclusion, nonwhite, hypertension, previous PPH, delivery by emergency caesarean section, multiple pregnancy and maternal admission to hospital ${ }^{13}$. In this study risk factors identified were multi parity, women aged of second decade, absent or irregular antenatal checkup or took irregular antenatal checkup, anaemia. Low status of women who do not attend antenatal care in a given health unit but are referred there when they developed life threatening obstetric complications, contribute significantly to maternal morbidity ${ }^{12}$. Induced abortions conducted by untrained village midwives are still a major cause of morbidity in the developing countries ${ }^{14}$.

This study shows that $43 \%$ of the patients are admitted due to eclampsia and the second highest cause is PPH (17\%), this is consistent with other studies. In South Africa, the most common initiating obstetric conditions are hypertension $(26 \%)$, haemorrhage $(26 \%)$, abortion or peurperal sepsis $(20 \%)^{4}$. In India, common causes of severe maternal morbidity are haemorrhage, hypertensive disorder, sepsis and obstructed labour. The proportions of these conditions are similar to those reported from other developing countries ${ }^{15}$. However, the study from West Africa reported a higher proportion of dystocia (30\%) as the second most common cause after haemorrhage. Studies from Europe have reported haemorrhage and hypertensive disorder as the most common cause in their region ${ }^{16}$.
Moderate to severe anaemia, which are observed in a very high proportion (moderate $46 \%$, severe $12 \%$ ), accompanied by other cause of SAMM. Severe anaemia alone is responsible for SAMM in $1 \%$ cases in this study, but it worsen the condition in association with other diseases like PPH. Only the study by Oladopa et el, classified anaemia separately, they reported it as a cause in about $4 \%$ of near miss cases. Other studies based on the disease specific criteria of severe maternal morbidity have not categorized severe anaemia as a separate condition $^{17}$.

Surgical interventions as LUCS (60\%), D\&C (20\%), salphingoophorectomy (3\%), hysterectomy (3\%) etc are needed for better management of SAMM. Only 13\% are normal deliveries. Prenatal death of the babies is also related with it. Extensive medical intervention is also needed regarding antibiotics, antihypertensive drugs, uterotonic drugs, sedative. Zwart et el, showed that caesarean section and induction of labour which were often performed because of compromised maternal condition. Preterm birth is also related ${ }^{10}$.

The patients who needed blood transfusion among them $24.5 \%$ patients needed more than 4 units of blood. In Netherland, major obstetric haemorrhage is estimated at $29 \%$ and these cases also required 4 units of blood ${ }^{10}$.

According to this study, only 4\% patients needed ICU admission. Bibi et el, shows $1.34 \%$ of obstetric patients are transfer to general ICU, corresponding to $1.34 \%$ and $1.4 \%$ of developing country reports. However rates seem to be slightly raised from 0.026 and 0.17 documented from developed world ${ }^{18}$.

This study highlights the facts that severe maternal morbidity cases place a significant burden on health resources and reflects the quality of health care available in our country. Eclampsia, severe preeclampsia, haemorrhage, sepsis, obstructed labour, ectopic pregnancy are major cases for severe maternal morbidity. These cases causes residual disability like chronic hypertension, hysterectomy, salphingoophorectomy, heart failure, renal failure and Sheehan's syndrome. Therefore these cases should be identified and treated without delay in order to improve fetomaternal outcome.

Severe obstetric morbidity and its relation to mortality may be more sensitive measures of pregnancy outcome than mortality alone ${ }^{13}$. Reduction of severe maternal 
morbidity seems a mandatory challenge ${ }^{10}$. Including SAMM in maternal death audit increase rapidity with which health system problems can be identified ${ }^{19}$.

\section{Conclusion:}

Most of the patients of this study are in second decade and in their second pregnancy, which is not usually regarded as a risk factor for obstetric complications. This signifies that every pregnancy should be monitored vigilantly. Proper medical and surgical intervention, improving awareness and education about the danger sign of pregnancy, antenatal and delivery care by skilled birth attendant could be some positive intervention to prevent SAMM and reduce the complication. Severe maternal morbidity is an indicator of the quality of obstetric care. Proper auditing of SAMM will be helpful to improve quality of care and ensure better survival.

\section{Reference:}

1. Jahan S, Begum K, Shaheen N, Khondokar M. Near-Miss/ Severe acute maternal morbidity (SAMM): A new concept in maternal care. J Bangladesh Coll Phys Surg 2006; 24: 29-33.

2. Ronsmans C, Filippi V. Revewing severe matrenal morbidity: learning from women who survive life threatening complications. In: Beyond the numbers, Geneva, WHO,2005.

3. Mental GD, Buchmann E, Rees H, Pattinson RC. Severe acute matrenal morbidity: A pilot study of a definition for a near miss. Br. J Obstet Gynaecol 1998 Sep;105: 985-90.

4. Prual A, Bouvier-Colle MH, De Bernis L, Breart G. Severe maternal morbidity from direct obstetric causes in West Africa: Incidence and case fatality rates. Bull World Health Organ 2000; 78: 593-602.

5. Brenis DL, Dumont A, Bouilin D, Gueye A, Dompnier JP, Bouvier Colle MH. Matrnal morbidity and mortality in two different populations of Senegal: a prospective study (MOMA Survey) BJOG 2000 Jan, 107(1)68,74.

6. Robert C, Pattinson and A Melin Gulmezogle. WHO systemic review of maternal morbidity: the prevelence of severe acute maternal morbidity (near miss). 17 Aug 2004.

7. Filippi V, Alihonou E, Mulkantaganda S, Grahan W, Ronsmans C. Near misses: Maternal morbidity and mortality. (Letter) Lancet, 1998; 35: 145-146.
8. Thaddeaus S, Maine D. Too far to walk: maternal mortality in context. Soc Scin Med 1994; 38:1091-1110.

9. Ronald T. Strand. Severe maternal morbidity in Angola, studies on postpartum haemorrhage, jaundice and clinic-bases audit. Department of Public Health Sciences, Division of International Health (HCAR), Karolinska Institute, Stockholm, Sweden. 2005.

10. Zwart J J , Richters J M, Ory F, Vries J I P, Bloemenkamp K W $\mathrm{M}$, Roosmalen J V. Severe maternal morbidity during pregnancy delivery and peurperium in the Netherlands: a nationwide population-based study of 371000 pregnancies. www.blackwellpublishing.com/bjog. 2008 Feb.

11. Schutte J M, Schuitemaker N E W, Roosmaker J V, Steegers E A P. Substandard care in maternal mortality due to hypertensive disease in pregnancy in the Netherlands. www.blackwellpublishing.com/bjog.2008 Jan.

12. Keye D, Mirembe F, Aziga F, Namuleme B. Maternal mortality and associated near misses among emergency intrapartum obstetric referrals in Mulago Hospital, Kampala, Uganda. East Afr Med J 2003: 80-144-149.

13. Geller SE, Rosenberg D, Cox SM, Kilpatrick S. Defining a conceptual framework for near miss maternal morbidity. J Am Med Women Assoc 2002 Summer; 57 (3): 135-9.

14. Khosla AH, Dahiya K, Sangwan K. Maternal mortality and near miss in rural nprth India. Inf. J Gynaecol Obstt 2000; 68: 163-164.

15. Gandhi MN, Welz T, Ronsmans C. Severe acute maternal morbidity in rural South Africa. Int J Gynaecol Obstet 2004; 87: 180-7 [Medline].

16. Brace V, Penny G, Hall M. Quantifying severe maternal morbidity: a Scottish apopulation study. Br J Obstet Gynaecol 2004; 111: 481-4.

17. Olodopa OT, Sule-Odu AO, Olatunji AO,Daniel OJ. "Near miss" obstetric events and maternal death in Sagamu, Nigeria: a retrospective study. Reprod Health 2005; 2: 9 [Mdline].

18. Bibi S, Menon A, Sheikh JM, Qureshi AH. Severe acute matrnal morbidity and intensive care in a public sector university hospital of pakistan. J Ayub Med Coll Abborttabad 2008; 20 (1).

19. Waterstone $\mathrm{M}$, Bewley $\mathrm{S}$, Wolfe C. Incidence and predictors of severe obstetric morbidity: case control study. BMJ 2001; 322: 1089-1094. 